\title{
PESTS, PLAGUES, AND PATENTS
}

\section{Timo Goeschl}

University of Cambridge
Timothy Swanson

University College London

\begin{abstract}
The paper investigates the interaction between dynamic forms of incentive mechanisms (patent systems) and dynamic forms of problems (adaptations of pests and pathogens). Since biological problems recur, the design of the incentive mechanism must take into consideration: a) the need for investments into R\&D that take into account the impermanence of the solution concepts; and b) the impact of this impermanence on the anticipated lifespan of any patent awarded for an innovation. The results indicate that patent systems must be carefully tailored to the nature of the problem under consideration. (JEL: C7, H0, H3, Q38)
\end{abstract}

\section{Introduction}

Human interventions within the biological world produce natural responses that automatically erode the effectiveness of the initial intervention. This effect is seen in the phenomenon of antibiotic resistance in the health context, or in the phenomenon of pest resistance in the agricultural context. These responses from nature are predictable and automatic because, when we choose to make a biological resource more prevalent than it would otherwise be, we are simultaneously selecting higher rates of prevalence for the pests and pathogens that prey upon that resource. These pests and pathogens will prosper by reason of our choices, and erode any gains from the initial intervention, unless we are able to intervene once again in a way that will restore the original gain. Thus, by intervening within the biological world, we are committing ourselves to a continuing race of innovation against nature.

Sustaining production in the face of these contests of biological innovation is the essence of the task that society assigns to the biotechnological industries. The biotechnology industries do so by generating innovations: solutions to these recurring problems. Just as in many other R\&D intensive industries, this one operates within a patent-based system of incentives for innovation. However, in

Acknowledgments: The authors would like to thank the many individuals who have commented upon this work, including Philippe Aghion, Gardner Brown, and David Simpson. We would also like to recognize the institutions that have supported the research effort, including the European Science Foundation and the European Union Research Division (BioEcon).

E-mail addresses: Goeschl: TG203@cam.ac.uk; Swanson: Tim.Swanson@ucl.ac.uk. 
other R\&D industries, the solutions generated can last forever. This quality of "durability" gives rise to the essentially cumulative nature of technological progress in other sectors and is captured in the concept of a "quality ladder" (Grossman and Helpman 1991). In the presence of evolving pests and pathogens, solutions are transient and temporary phenomena in an exercise thatmetaphorically - appears much more like a treadmill than a ladder. The fundamental question is then whether a patent system designed for the world of durable solutions is an appropriate system for rewarding private firms for innovations that will not last.

Under patent-based R\&D systems, firms compete for patents that provide revenue streams until such time as another innovation renders that patent obsolete. In the biotechnology industry these patents will be displaced by a competitive firm's creation or a competitive pathogen's adaptation.

How will firms operating under a patent system respond to the challenge implied by these biological contests? Are patents adequate for targeting the achievement of the gains sought by society? The distinction between the social objectives regarding biotechnology and the patent-based incentives to pursue them is the focus of this paper.

In this paper we discuss some of our recent work in the analysis of the management of the R\&D process within the biotech sector (Goeschl and Swanson 2002a, 2002b, 2002c). We commence in Section 2 with a description of the intersection of the systems of dynamics represented by biological problems and patent-based incentives. In Section 3 we describe the social objective with regard to the management of this sector, and the optimal scale of investment in R\&D. In Section 4 we discuss the patent-based incentives for investment in R\&D, and demonstrate how they differ from the socially optimal outcome. In Section 5 we summarise the nature of the general problems of pests and patents, both with regard to scale and with regard to the speed of technological change.

\section{Resistance Problems and R\&D Policies: The Intersection of Dynamic Systems}

In this section we describe the dynamic system that evolutionary biologists use to characterize the realm within which biotechnology operates, and how this system intersects with the dynamics inherent within a patent-based incentive system for innovation. Here biotechnology will refer to the use of biological resources as inputs into the research and development for the development of solutions to biological problems within the context of evolutionary processes. Biological problems are perceived by evolutionary biologists as zero-sum games between competing predators. Thus an infestation or infection simply represents the appropriation of a larger share of the available surplus by a competing organism. The evolutionary process is the combined result of the 
processes of selection, adaptation and reproduction. Thus the application of a particular pesticide or pharmaceutical to a pest population simply selects disproportionately those in the population which are resistant to it, resulting in disproportionate reproduction by those resistant, and consequently in the observed adaptation of resistance over time.

The biotechnology industries engage in an ongoing contest to solve these biological problems against the background of these evolutionary processes. For example, the pharmaceutical industry deals with such problems in its research into antibiotics, where it attempts to halt the progress of pathogens successfully reproducing themselves within the human population. After application of an antibiotic, the industry must then deal with the consequences of selection and adaptation, when the pathogen population demonstrates resistance to the antibiotic (Laxminarayan and Brown 2001). The agricultural industry deals with such problems in its research into new plant varieties. It is a common observation in agriculture that widely planted modern crop varieties have a commercial live span of about five to seven years, requiring the continuous production of new varieties in order to replace those registering declining yields. The commercially obsolete plant variety, as host to an increasingly successful pest population, is one that is registering the same problem that is preying on the human population in the pharmaceutical context. Again, the introduction of the new plant variety induces the development of resistance within the pest population by reason of selection and adaptation, and the new variety begins its decline (Evans 1993; Scheffer 1997). To illustrate these points, Table 1 lists a set of chemical controls for which resistance has been observed to develop on a predictable basis (Anderson and May 1991).

Evolutionary theory and empirical evidence indicate that one unusual characteristic of biological problems is their refusal to go away (Munro 1997). When a solution has been ascertained and applied within the biological world, the nature of the biological world is such that it will commence immediately to erode the usefulness of that application. Adaptation of biota (pests and pathogens) to widely-used pharmaceuticals and plants is a "fact of life," and it implies that the widespread use of any biotechnology must necessarily imply its own eventual demise (Weitzmann 2000). Well-established laws of evolution exist to describe this type of pathogen response driven by scale of application (Hofbauer and Sigmund 1988).

A second type of pathogen response has received increasing attention in the context of the recent debate over the commercialisation of genetic modifications. Here the driving factor is the speed at which new technologies are developed and applied. The impact of the speed of innovation on pathogen evolution is more speculative and various possibilities have been suggested. One possibility discussed in the literature is that an increasing pace of technological change will simply increase the speed of response by pathogen populations (Stenseth and Maynard Smith 1984) or competing genes (Frank 2000). Biologists refer to such "contests of innovation" as Red Queen Contests, in which it 
Table 1. Characteristic Time for the Appearance of Resistance in Some Specific Biological Systems (From Anderson ANd May 1991)

\begin{tabular}{|c|c|c|c|}
\hline \multirow[b]{2}{*}{ Species } & \multirow[b]{2}{*}{ Control agent } & \multicolumn{2}{|c|}{ Time to resistance } \\
\hline & & Generations $^{\mathrm{a}}$ & Years \\
\hline \multicolumn{4}{|l|}{ Avian coccidia } \\
\hline \multirow[t]{6}{*}{ Eimeria tenella } & Buquinolate & $6(<6)$ & 1 \\
\hline & Glycarbylamide & $11(9)$ & $<1$ \\
\hline & Nitrofurazone & $12(5)$ & 7 \\
\hline & Clopidol & $20(9)$ & 6 \\
\hline & Robenicline & $22(16)$ & 10 \\
\hline & Nicarbazin & $35(17)$ & 27 \\
\hline \multicolumn{4}{|l|}{ Gut nematodes in sheep } \\
\hline \multirow[t]{2}{*}{ Haemonchus contortus } & Thiabendazole & 3 & $<1$ \\
\hline & Cambendazole & (4) & $<1$ \\
\hline \multicolumn{4}{|l|}{ Ticks on sheep } \\
\hline \multirow[t]{3}{*}{ Boophilus microplus } & DDT & 32 & 4 \\
\hline & $\mathrm{HCH}$-dieldrin & 2 & $<1$ \\
\hline & sodium arsenite & & 40 \\
\hline \multicolumn{4}{|l|}{ Black flies (Japan) } \\
\hline Simulium aokii & DDT + Lindane & & 6 \\
\hline Simulium damnosum & DDT & & 5 \\
\hline \multicolumn{4}{|l|}{$\begin{array}{l}\text { Anopheline mosquitoes } \\
\text { (different localities) }\end{array}$} \\
\hline \multirow[t]{2}{*}{ Anopheles sacharovi } & DDT & & $4-6$ \\
\hline & Dieldrin & & 8 \\
\hline An. maculipennis & DDT & & 5 \\
\hline \multirow[t]{2}{*}{ An. stephansi } & DDT & & 7 \\
\hline & Dieldrin & & 5 \\
\hline An. culicifacies & DDT & & $8-12$ \\
\hline An. annuaris & DDT & & $3-4$ \\
\hline \multirow[t]{2}{*}{ An. Sundaicus } & DDT & & 3 \\
\hline & Dieldrin & & $1-3$ \\
\hline \multirow[t]{2}{*}{ An. quadrimaculatus } & DDT & & $2-7$ \\
\hline & Dieldrin & & $2-7$ \\
\hline
\end{tabular}

${ }^{a}$ The figures give the number of generations before a majority ( $>50$ percent) of the individuals in the population are resistance to the control agent. In brackets are the number of generations before resistance is first observed (usually $>5$ percent of individuals resistant).

is necessary to innovate more and more rapidly merely to maintain parity within the contest (Maynard Smith 1976). Another possibility is that an increased pace of technological change might slow the rate of response from the pathogen population, or possibly eliminate the population altogether (the so-called 'magic bullet'). Depending on the view taken, differences in expectations concerning the impact of the pace of biotechnological change will indicate that very different sorts of policies would be optimal.

In a context such as this where the scale and speed of technological change matter, the meaning of technological progress is much less straightforward. If the widespread use of a technological advance must necessarily imply the increasing rate of arrival of problems, then what is to be the measure of success? Think of the biotechnology sector as engaged in a race by the innovator up the 
"down" escalator. Then success in the race must be measured relative to actual progress up the escalator, not just steps taken by the innovator. Imagine as well that the escalator belt runs freely, so that quicker or larger steps by the innovator simply results in bringing the stairs down more quickly. Given that individual attempts at progress result in both discrete moves forward and an increasing pace of the background contest, the full impact of an innovation must be discerned by its aggregate impact across time. It is possible that small initial advances might ultimately aggregate into large net losses.

In sum, this paper conceptualizes the biotechnology sector as that area of human enterprise dedicated to the maintenance of the stability of the "biological production sector" against a background of competing organisms continually evolving to introduce new biological problems. It pursues this objective by making investments that increase the rate of arrival of solutions to such problems. One of the primary investment decisions of the biotechnology sector is to determine the optimal amount of biological resources devoted to these objects of future sustainability as opposed to current production.

Having described the role of the biotechnology sector in society as that of generating innovations within this biological contest, we turn briefly to the role of the industrial contest that motivates the biotechnology industry to generate these innovations. The biotechnology sector is motivated by the pursuit of limited-term monopolies from the conferment of patents upon its innovations. In accordance with patent law, monopolies of a specified duration are allowed for useful innovations of a specified magnitude, i.e., representing a certain minimum level of advance. In focusing on patent-based mechanisms for motivating decentralized $R \& D$, this paper is related to the literature on contests of innovation well known from the theory of industrial organization (Tirole 1988).

The specific framework adopted here is the model of a sector engaged within a process of creative destruction (Aghion and Howitt 1992). With regard to the industrial contest, the one significant modification that we apply within this framework is to incorporate the possibility of another overlaid process of ongoing obsolescence deriving from forces within the biological, as opposed to the industrial, world. The stream of rents from an innovation may be truncated by reason of a competitive innovation originating in either contest, biological or industrial. We term the impacts of the biological contest on the industrial innovation contest a process of adaptive destruction. Against this background of creative and adaptive destruction, the biotechnology firm must compete to innovate in order to remain within the industry. Hence, it is the intersection of the dynamic systems represented by biological problems and patent-based policies that generate the ultimate incentives that motivate the biotechnology industry. How these unusual dynamics produce outcomes, and how these outcomes relate to the ultimate objectives society holds for the sector are the subjects of this paper. In the next section we set out the basics of a biotechnology sector, its role in addressing biological problems and the optimal scale of investment required for its operation. 


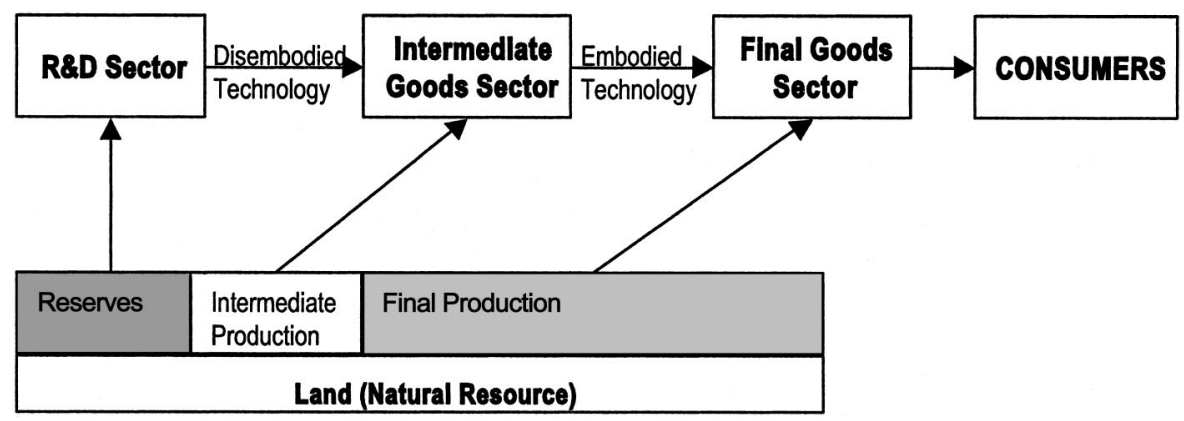

Figure 1. The Biotech Sector Within a Three-Tiered Production System

\section{The Social Planner's Objective in the Biotech Sector}

In this model of the biotech sector we are looking at the role of the underlying research and development $(\mathrm{R} \& \mathrm{D})$ process that sustains the production sector in the "life sciences." The biotechnology sector performs this task, explicitly, by conducting R\&D to provide a flow of necessary innovations to sustain society in the contest of biological innovation. Implicitly it is determining the level of investment into R\&D, including the level of investment of biological resources, and consequently, given a fixed endowment of land, the relative sizes of the production and reserve sectors. In between the research and production sectors, there is an intermediate goods sector whose sole role is to embody the information developed in the research sector for application within the production sector.

Figure 1 gives this depiction of the biotechnology sector and its role in this production system. Here the biotechnology sector performs R\&D and uses the essential natural resource (here, land) as an input into its research activities. Innovations result in new technology that is embodied within patented products in the intermediate sector; the intermediate good also requires a small allocation of the essential input for production. Finally, the intermediate good is then used in the final goods production sector in combination with the essential natural resource in order to produce the goods that are marketed to consumers.

Social Planner's Objective: The social planner's objective is then to allocate lands to the reserve sector in sufficient quantities to provide the R\&D sector with the capacity to combat biological resistance within the production system. Integrating over time allows the derivation of the present value of social welfare from the allocation of land between the reserve (v) and production sectors.

$$
U(\nu)=\frac{A_{0} F(\bullet)}{r-\left[\phi i(\nu)-\lambda a(\nu) \gamma^{-1}\right](\gamma-1)}
$$


The numerator of (9) is the initial level of production: it is composed of the initial level of technology and the initial level of production (given lands invested in the production sector). The denominator of (9) is the trajectory of production: it is composed of the rate of innovation in the $\mathrm{R} \& \mathrm{D}$ sector (given investment in reserves) net of the rate of adaptation or resistance by pests and pathogens. The appendix demonstrates that, even if the social objective is restricted to maximum production over time, the social planner's objective will be an allocation of land to both functions: production and reserves. (see also Weitzman 2000). Taking the limits of Equation (9) with respect to land allocation is sufficient to establish this basic proposition.

Proposition 1: If all available land is converted to use in the final production sector, social welfare converges to zero. If all available land area is allocated to reserves, social welfare converges to zero.

The optimal scale of investment in the R\&D sector will have to balance the foregone production (reduction in the numerator of (9)) against the decreased growth trajectory from reduced innovation in the R\&D sector (reduction in the denominator of (9)). This is set out in equation (10).

Socially Optimal Scale of $R \& D$ Investments: Maximizing equation (9) with respect to reserve size $\nu$ results in the following optimality condition:

$$
\nu^{* S}: \quad \frac{F_{\nu}(\bullet)}{\beta+z}=\frac{\left[\phi i_{\nu}(\nu)-\lambda a_{\nu}(\nu) \gamma^{-1}\right] F(\bullet)}{r-\left[\phi i(\nu)-\lambda a(\nu) \gamma^{-1}\right]}
$$

The social planner balances the losses in production against the gains in innovation, wherever they accrue within society. It is important to note that the social planner is able, at any given point in time, to trade-off these changes in the level of current production against the changes in the trajectory of future production.

\section{Firm Decision Making Regarding Scale of R\&D}

A decentralized $R \& D$ industry requires substantial policy intervention to be operable. This is because the benefits generated from investments in $R \& D$ are usually inappropriable or very inexactly appropriable, and this leads to suboptimal levels of investment in R\&D (Arrow 1962). One policy response to this problem is the creation of a regime of monopoly rights in the marketing of intermediate goods that embody some of this information, e.g., patent rights. As with those in other sectors of the economy, innovations in the biotechnology industry are rewarded using the same regime of patents. Here, we examine the incentives created by a patent system for investment in biotechnological innovations 
when the size of innovations is fixed at a level to ensure that all innovations are drastic. The question is: How will a private biotechnology firm within an industry of the type described above respond to the incentives to invest in R\&D?

Private Patent-based Optimal Investment: The allocation of resources to the biotech sector is optimal for a private firm where the marginal loss in final production through additional land in reserves equals the private net present value of the gross marginal increase in monopolistic rents in the final goods sector generated by the reserve sector. Differentiating Equation (16) with respect to reserve size, we arrive at the following optimality condition for the private firm in a patent-motivated industry (of $n$ firms).

$$
\nu^{* p}: \quad \frac{F_{\nu}(\bullet)}{\beta}=\phi i_{\nu}(\nu) \cdot \frac{\gamma \frac{\left[F_{v}(\bullet)\right]^{2}}{-F_{\nu \nu}(\bullet)}}{r+(n-1) \phi i(\nu)+\lambda a((n-1) \nu)}
$$

As in (10), the LHS of (17) shows the marginal value of land allocated to production, although in the present case of private allocation the demand for land in the intermediate sector is neglected. The RHS the marginal value of land allocated to reserve status. The marginal value of lands as reserves is equal to the expected value of monopoly rents accruing to the successful innovator by reason of the allocation of an additional unit of land to $R \& D$, discounted at the private firm rate that includes not only the opportunity cost of capital but also the anticipated effects of patent obsolescence (deriving from either the processes of creative or adaptive destruction).

Now that we have derived the alternative decision making rules for social and patent-based decision making regarding resistance problems, it is possible to compare how these alternative decision making systems respond to the fundamental determinants of resistance problems. These are fully discussed in (Goeschl and Swanson 2002a). What is of interest here is the performance of the patent system of rewarding innovations with respect to the fundamental problem in biotechnology, namely the recurrence of problems through endogenous adaptation. The following proposition demonstrates that this performance is problematic.

PROPOSITION 2: Under the criterion of the social optimum, an increased rate of adaptation requires an increased allocation of resources to $R \& D$. Under a patent regime, an increased rate of adaptation leads to a reduced allocation of resources to $R \& D$ by industry.

Patent mechanisms generate a perverse response to an increase in the rate of adaptation by pathogens. Investment in R\&D is society's instrument for responding to problems of resistance, and so the marginal benefits from R\&D will increase as the rate of biological adaptation increases. From industry's perspective, when biological adaptations are more frequent, then patents become obsolete more 


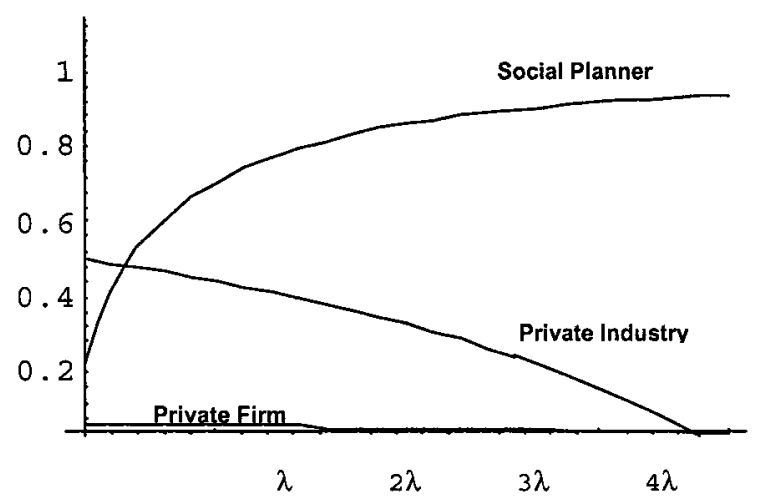

FIGURE 2. Investments in R\&D for Varying Rate of Biological Innovation

quickly, thus providing reduced incentives for investments. Increasing rates of adaptation imply reduced time horizons for product usefulness, and hence a truncated flow of future benefits. This conflict is illustrated in Figure 2.

How serious is this problem? For one, it indicates that in those areas where the biological response to the broad application of productivity-enhancing innovations is most rapid, the problem of private under-investment in R\&D under a patent system is most pronounced. Secondly, to the extent that increasing rates of innovation implicitly select for a larger number of different pathogens, this may lead to an endogenous increase in the rate of adaptive destruction. In both cases, society faces a contest of innovation that cannot be suspended.

IPR systems are very poor mechanisms for providing incentives in such contests of innovation. The induced response from nature implies an expectation that any innovation's life span will be short, and this reduces the incentives to invest in innovation from the outset. If, for some reason, society does make an initial attempt to achieve growth in production in the biological sphere, the IPR system provides an increasingly diminishing incentive to attempt to remain within the contest of innovation that results. Just as society becomes reliant on the biotechnology sector to address the resulting problems, the biotechnology sector becomes increasingly less motivated to pursue those problems.

\section{Conclusion: Optimal Choices Regarding the Scale and Rate of Technological Change}

The preceding section gives an idea of the nature of the problems that patentmotivated incentive mechanisms generate in the regulation of $R \& D$ within this sector. The source of this problem is clear. The problem of optimal scale of $R \& D$ concerns the trade-off between current levels and future trajectories of 
production. Any problem that arises only within the future affects only one side of this equation. The fundamental nature of many biological solutions is their impermanence, and so it is very important from the social perspective that an adequate scale of investments occurs in order to provide for a future flow of solution concepts. The problem with a patent mechanism is that it does not take into account the impact of biological competitors on the expected rents generated by patents. The reliance on a certain level of "permanence" implicit in the customary patent length (i.e., about 20 years) further reduces the compensation of an innovation. If biological adaptations occur more frequently than that, then the period of patent-based compensation is reduced accordingly. An increasing expectation of impermanence (i.e., an increasing rate of adaptation) will result in reduced levels of investment, precisely when those investments are most important. Time-delimited patents are a poor fit with the fundamental nature of the problem.

As the preceding analysis has shown, the fact that the processes of innovation and adaptation depend on the scale of application has significant implications for the optimal allocation of land to production and R\&D. It is also possible to generalize these results by considering linkages between the innovation and adaptation processes. These linkages introduce a selection mechanism into the model that depends on the rate of technological progress. This rate of progress is captured in the step size of productivity increases between two sequential technological stages. In the escalator metaphor we introduced at the outset of the paper, the issue here concerns how a biological system might respond, if society were to attempt to leap up the escalator two steps at a time (i.e., by taking larger steps). Will the escalator (running on a loose rather than fixed belt) respond by running even faster beneath our feet? Or, will it continue to run at the same pace, or even slow? The advantage of taking technological "leaps" will depend on the responsiveness of the system within which we are moving. The expectations that society has concerning the response of the system will determine whether it is optimal to pursue such "leaps," or to keep technological change progressing at a smooth and continuous pace. The differences in such expectations is the source of the debate over "genetically modified organisms" and other biotechnological applications (Goeschl and Swanson 2002b). If there are systemic responses to discontinuous technological change, then this also has important implications for the management of R\&D policy (O'Shea and Ulph 2002; Swanson 2002).

The intersection of the dynamics of the R\&D sector with the dynamics of the patent mechanism generates some interesting outcomes. It demonstrates that, in general, patent systems should never be viewed as a "one size fits all" sort of incentive mechanism. Mechanism design for dynamic problems requires a lot more careful thought and enquiry (Goeschl and Swanson 2001; Kremer 2000; Mason and Swanson 2002). 


\section{Appendix}

\section{A.1. Basic Modelling Assumptions}

Final goods production is of a fixed proportions type, implying a fixed amount $(\beta)$ of the intermediate input $(\mathrm{x})$ being combined with each unit of the natural resources input (L), with $d$ denoting the proportion of $L$ allocated to final good production. The production function has the properties:

$$
y_{t}=A_{t} F\left(x_{t}\right)
$$

with $F(0)=0, F x>0$ and $F x x<0$ with $A_{t}$ denoting the technological stage at $t$. The intermediate goods sector is also characterized by a fixed-proportions production function where the proportion $g$ of $L$ allocated to intermediate good production generates an increase in the production of the intermediate good $x$ proportional to the factor $z$. This implies that

$$
x_{t}=\frac{d_{t}}{\beta}=\frac{g_{t}}{z}
$$

The R\&D sector consists of an $n$-firm industry engaged in a patent race. The timing of innovations is governed by a Poisson process denoted by $\phi$ and the frequency of innovation increases with the proportion $v$ of $L$ allocated to $\mathrm{R} \& \mathrm{D}$ and decreases with the targeted innovation size $\gamma$. Innovations hence arrive at a rate $\phi i(v, \gamma)$ per time period where $i(v)$ with $i(0)=0, i_{v}>0, i_{\gamma}(v, \gamma)<0$ and $i_{\gamma \gamma}(v, \gamma)<0$ is an innovation production function following standard assumptions. An innovation shifts the technological stage up by factor $\gamma>1$ such that $\mathrm{A}_{\mathrm{I}+1}=\mathrm{A}_{\mathrm{I}} \gamma$ with index $I$ denoting the current level of technology in use in final goods production.

The dynamic process of biological innovations forced by selection pressure is also modeled as a Poisson process represented by $\lambda$ and an induced evolution function $a(x, \gamma)$. Pathogens therefore adapt to and overcome current technologies at a rate of $\lambda a(x, \gamma), a_{x}(x, \gamma)>0$. A "biological innovation" is normalized so that a single innovation eliminates the relative advantage of the current technology. This results in a shift of $\gamma^{-1}$ in productivity. Thus, with $D$ denoting the stage of biological innovations (i.e., depreciation), $A_{D+1}=A_{D} \gamma^{-1}$. With $s$ denoting the current technological stage given a history of innovations and adaptations, the net state of productivity at stage $s$ is then,

$$
A_{s}=A_{0} \gamma^{s}=A_{0} \gamma^{I-D}
$$

\section{A.2. Social Planner's Problem}

The social objective society consisting of a continuum of individuals of mass 1 , each with an intertemporal utility function linear in the consumption of final good y, of the type: 


$$
u(y)=\int_{\tau=0}^{\infty} e^{-r \tau} y d \tau
$$

subject to constraint (for $L=1$ ) that

$$
1=v+d+g
$$

From (3) and (5) follows that $x=(1-v) /(\beta+z)$ such that $a(x)$ can be expressed as $a(v)$ with $a_{v}<0$. We use the probability distributions $\Pi(I, t)$ (the probability of $I$ technological innovations by the time $t$ ) and $\Pi(D, t)$ (the probability of $D$ biological innovations by the time $t$ ) defined as:

$$
\begin{aligned}
\Pi(I, t) & =\frac{1}{I !}[\phi i(\nu, \gamma) t]^{I} e^{-[\phi i] t} \\
\Pi(D, t) & =\frac{1}{D !}[\lambda a(\nu, \gamma) t]^{D} e^{-[\lambda a] t}
\end{aligned}
$$

we can combine the expressions (1)-(7) and aggregate to restate the social objective of maximum production as follows:

$$
\underset{\nu, \gamma}{\operatorname{Max}} U=\int_{t=1}^{\infty} e^{-r t} \sum_{I=0}^{\infty} \sum_{D=0}^{\infty}[\Pi(I, t) \cdot \Pi(D, t)] A_{s} F(x) d t
$$

Integrating equation (8) over real time and making use of (4); we arrive at the following expression for the present value of social welfare from the allocation of this input between these sectors.

$$
U=\frac{A_{0} F(\bullet)}{r-\left[\phi i(\nu, \gamma)-\lambda a(\nu, \gamma) \gamma^{-1}\right](\gamma-1)}
$$

where $F(\bullet)$ is $F\left[\beta^{-1}(1-v-g)\right]$ and $a_{v}<0$ from (5).

From equation (9) a number of policy-relevant propositions result. We first prove proposition 1 by examining the limiting cases of allocating land to the reserve sector in terms of their implications for welfare.

\section{A.3. Proof of Proposition 1}

Total conversion of land into intensive use implies that the share of land allocated to the final sector, $x$, is one. From $x=1$ follows that all reserve lands are converted such that $v=0$. Taking the limit of equation (9) with respect to $\nu \rightarrow 0$, we get 


$$
\lim _{\nu \rightarrow 0} U=\lim _{\nu \rightarrow 0} \frac{A_{0} F[\bullet]}{r-\left[\phi i(0)-\lambda a(0) \gamma^{-1}\right](\gamma-1)}=0
$$

An allocation that does not result in a positive investment in reserves for R\&D implies an intrinsic discount rate of infinity. The intuition is that the expected rate of biological adaptation rises to infinity in such a setting, implying practically immediate obsolescence of production technologies and no generation of further innovations.

Taking the limit of equation (9) with respect to $\mathrm{v} \rightarrow 1$, we get

$$
\lim _{\nu \rightarrow 1} U=\lim _{\nu \rightarrow 1} \frac{A_{0} F[0]}{r-\left[\phi i(1)-\lambda a(1) \gamma^{-1}\right](\gamma-1)}=0
$$

An allocation that does not allocate land to productive use denies consumptive utility to society and hence results in no welfare creation in the economy. Land in intensive use is therefore necessary to generate instantaneous returns to land assets.

\section{A.4. Social Optimum}

Under the assumption of an exogenously given innovation size $\gamma$ large enough to ensure that only drastic innovations occur, maximizing equation (9) with respect to reserve size $v$ results in the following optimality condition under scale-dependent evolution:

$$
\frac{F_{\nu}(\bullet)}{\beta+z}=\frac{\left[\phi i_{\nu}(\nu)-\lambda a_{\nu}(\nu) \gamma^{-1}\right] F(\bullet)}{r-\left[\phi i(\nu)-\lambda a(\nu) \gamma^{-1}\right]}
$$

at the optimum with $F(\bullet)=F\left[\beta^{-1}(1-\nu-g)\right]$.

\section{A.5. Biotechnology Industry Problem}

Assuming a perfectly competitive final goods sector, the optimal amount of good $x$ produced is the level of output that maximizes revenues minus the cost of producing the intermediate good on land $g(x)$, where land commands the price $p$ per unit.

$$
x_{s}^{*}=\operatorname{argmax}\left[A_{s} F_{x}(x) x-p(x) g x\right]
$$

With the price of land $p$ a function of $x$, then

$$
x^{*}=-\frac{F_{x}(x)}{F_{x x}(x)}
$$

This means that monopolistic profits in the technological state $s, \pi_{s}$, would be: 


$$
\pi_{s}=-A_{s} \cdot \frac{\left[F_{x}\left(x_{s}^{*}\right)\right]^{2}}{F_{x x}\left(x_{s}^{*}\right)} \cdot\left(1-\frac{z}{\beta}\right)
$$

R\&D investments by each firm are carried out under a standard R\&D balancing condition taking into account the expected obsolescence of technological innovations (by reason of the processes of both creative and adaptive destruction)

$$
r V_{I+1}=\pi_{I+1}-(n-1) \phi i\left(\nu_{I+1}, \gamma\right) V_{I+1}-\lambda a\left(x_{I+1}, \gamma\right) V_{I+1}
$$

Rearranging (14) and making use of (3), we get the net present value of a single technological innovation

$$
V_{I+1}=\frac{\pi_{I+1}}{r+(n-1) \phi i\left(\nu_{I+1}, \gamma_{I+1}\right)+\lambda a\left(\nu_{I+1}, \gamma_{I+1}\right)}
$$

Land will be allocated by the patent holder in order to equalize returns in both the final goods sector and in R\&D.

$$
p=A_{s} \frac{F^{\prime}(\bullet)}{\beta}=\phi i\left(\nu_{s}, \gamma\right) \gamma V_{I}
$$

where $F(\bullet)$ is $F\left[\beta^{-1}(1-(n-1) v-g)\right]$. This condition (16) provides the intertemporal link between technological stages. Combining (4) with (15) and (16) and solving for the steady state and using (5) to simplify, we derive the optimality condition for the private firm's allocation of land to the reserve sector in the steady state of a decentralized economy.

$$
\frac{F_{\nu}(\bullet)}{\beta}=\phi i_{\nu}(\nu) \cdot \frac{\gamma \frac{\left[F_{\nu}(\bullet)\right]^{2}}{-F_{\nu \nu}(\bullet)}}{r+(n-1) \phi i(\nu)+\lambda a((n-1) \nu, \gamma)}
$$

\section{A.6. Proof of Proposition 2}

Proposition 2 can be easily proved through the comparative statics of equations (10) and (17). Taking the partial derivatives of (10) with respect to the variables specified, we see that the socially optimal amount of investment in biotechnology increases with (a) a decrease in the discount rate $r$, (b) an increase in the magnitude of the impact of an innovation $\gamma$, (iii) an increase in the arrival rate of technological innovations $\phi$ and (iv) — critically-an increase in the arrival rate of biological innovations $\lambda$. Conversely, the optimal level of investment by the individual biotechnology firm responding to patent-based incentives increases with (a) a decrease in the discount rate $r$, (b) an increase in the magnitude of the impact of an innovations $\gamma$, (c) an increase in the arrival rate of technological innovations $\phi$, and (d) - again critically_a decrease in the arrival rate of biological innovations $\lambda$. 


\section{References}

Aghion, P. and P. Howitt (1992). "A Model of Growth Through Creative Destruction." Econometrica, 60, pp. 323-351.

Anderson, R. M. and R. M. May (1991). Infectious Diseases of Humans: Dynamics and Control. Oxford Science Publications. Oxford: Oxford University Press.

Arrow, K. (1962). "Economic Welfare and the Allocation of Resources for Invention." In R. Nelson, ed., The Rate and Direction of Inventive Activity. Cambridge, Massachusetts: Harvard University Press.

Evans, L. T. (1993). Crop Evolution, Adaptation and Yield. Cambridge: Cambridge University Press.

Frank, S. A. (2000). "Polymorphism of Attack and Defense." Trends in Ecology and Evolution 15, pp. 167-171.

Goeschl, T. and T. Swanson (2001). "Lost Horizons: The Inappropriateness of the Patent System to Solve Recurrent Problems of Resistance in Antibiotics." Paper presented at American Economic Association meeting. New Orleans, January 2001.

Goeschl, T. and T. Swanson (2002a). "The Social Value of Biodiversity for R\&D." Environmental and Resource Economics, 22, pp. 477-504.

Goeschl, T. and T. Swanson (2002b). "The Management of the Pace of Technological Change: The Case of GMOs," mimeo. Department of Land Economy, University of Cambridge.

Goeschl, T. and T. Swanson (2002c). "Some Economics of Biotechnology." In Battling Resistance to Antibiotics and Pesticides: An Economic Approach, edited by R. Laxminarayan. Washington D.C.: Resources for the Future.

Grossman, G. and E. Helpman (1991). "Quality Ladders in the Theory of Growth." Review of Economic Studies, 58(1), pp. 43-61.

Hofbauer, J. and K. Sigmund (1988). The Theory of Evolution and Dynamical Systems. Cambridge: Cambridge University Press.

Kremer, M. (2000). "Creating Markets for New Vaccines Part I: Rationale.” NBER Working Paper W7716.

Laxminarayan, R. and G. Brown (2001). "Economics of Antibiotics Resistance: A Theory of Optimal Use." Journal of Environmental Economics and Management, 42(2), pp. 183206.

Mason, R. and T. Swanson (2002). "The Costs of Uncoordinated Regulation." European Economic Review, 46(1), pp. 143-167.

Maynard Smith, J. (1976). "A Comment on the Red Queen." The American Naturalist, 110, pp. 325-330.

Munro, A. (1997). "Economics and Evolution." Environmental and Resource Economics, 9, pp. 429-229.

O'Shea, L. and A. Ulph (2002). "Providing the Correct Incentives for Genetic Modification." In The Economics of Managing Biotechnologies, edited by T. Swanson. Dordrecht: Kluwer.

Scheffer, R. (1997). The Nature of Disease in Plants. Cambridge: Cambridge University Press.

Stenseth, N. C. and J. Maynard Smith (1984). "Coevolution in Ecosystems: Red Queen Evolution or Stasis?" Evolution, 38(4), pp. 870-880.

Swanson, T. (ed.). (2002). The Economics of Managing Biotechnologies. Dordrecht: Kluwer.

Tirole, J. (1988). The Theory of Industrial Organization. Cambridge, Massachusetts: MIT Press.

Weitzman, M. (2000). "Economic Profitability versus Ecological Entropy." Quarterly Journal of Economics, 115(1), pp. 237-263. 